\title{
BMJ Flemish adolescents' perceptions of open cigarette plain packaging: a qualitative study with focus group discussions
}

\author{
Guido Van Hal, ${ }^{1}$ Sofie Van Roosbroeck, ${ }^{1}$ Bart Vriesacker, ${ }^{1}$ Matheus Arts, ${ }^{2}$ \\ Sarah Hoeck, ${ }^{1}$ Jessica Fraeyman ${ }^{1}$
}

To cite: Van Hal G, Van Roosbroeck S, Vriesacker B, et al. Flemish adolescents' perceptions of cigarette plain packaging: a qualitative study with focus group discussions. BMJ Open 2012;2: 001424. doi:10.1136/bmjopen-2012001424

- Prepublication history and additional material for this paper are available online. To view these files please visit the journal online (http://dx.doi.org/10.1136/ bmjopen-2012-001424).

Received 4 May 2012 Revised 15 November 2012 Accepted 19 November 2012

This final article is available for use under the terms of the Creative Commons Attribution Non-Commercial 2.0 Licence; see http://bmjopen.bmj.com

\footnotetext{
${ }^{1}$ Medical Sociology and Health Policy, Department of Epidemiology and Social Medicine, University of Antwerp, Antwerp, Belgium ${ }^{2}$ Department of Psychiatry, University Medical Centre Groningen, Groningen, The Netherlands
}

\section{Correspondence to:} Dr Guido Van Hal; guido.vanhal@ua.ac.be

\section{ABSTRACT}

Objectives: To find out whether there is a potential impact of the appearance of a plain cigarette package on the smoking perceptions and behavioural intentions of Flemish adolescents.

Design: We performed a cross-sectional study using the qualitative method of focus group discussions.

Setting: Flemish adolescents.

Participants: We performed eight focus group discussions, in which 55 adolescents took part, 32 female and 23 male. Inclusion criteria were: Flemish male and female 15-year-olds to 16-year-olds and 17-year-olds to 18-year-olds attending regular highschool education or vocational training who were current or had ever been smokers.

Outcome measure (planned as well as measured): The opinions and perceptions of young Flemish smokers regarding the impact of cigarette packaging on their smoking behaviour.

Results: Plain packages are perceived as less attractive, cheap and unreliable for young people. Because of the unattractiveness of the plain packaging, the health warnings catch the eye much more strongly. Conclusions: In this first scientific study in Flanders on this topic, it emerged that plain packaging could be a strong policy tool to reduce the number of adolescents starting smoking. Validation of these findings by conducting a quantitative survey in the same target group is recommended.

\section{INTRODUCTION}

In 2008, more than one of four young Flemish people aged 15-24 years was a smoker: $16.9 \%$ were daily smokers and $7.5 \%$ were occasional smokers $(6.6 \%$ were exsmokers and $69 \%$ had never smoked). ${ }^{1}$ This means that of a total of 725000 young people aged 15-24 in Flanders in 2008, 122525 were daily smokers and 54375 were non-regular smokers. ${ }^{2}$

More specifically, in the group of Flemish 15 -year-olds to 16 -year-olds, $9.3 \%$ was a daily smoker in 2008. In the 17-year-olds to 18-year-olds, this was $19.2 \% .^{3}$ Half as many

\section{ARTICLE SUMMARY}

Article focus

- What is the impact of the appearance of a plain cigarette package on the smoking perceptions and behavioural intentions of adolescents?

- What motivates young people to choose a certain cigarette package?

- What is the visibility of the warning labels on original and plain packages?

Key messages

- Plain packaging is perceived as less attractive, cheap and unreliable for young people.

- Because of the unattractiveness of plain packaging, the health warnings catch the eye more effectively.

- In this first scientific study in Flanders on this topic, it emerged that plain packaging could be a strong policy tool to reduce the number of adolescents starting smoking.

Strengths and limitations of this study

- The qualitative research method gave us a unique insight into the opinions and perceptions of young Flemish smokers regarding the impact of cigarette packaging on smoking behaviour.

- We achieved saturation of the data.

- Our results are in line with studies in other countries.

- The plain package used in the focus group discussions, was not of optimal quality.

- The participants' nicotine dependence was not measured.

- We could not perform a validation of our findings by conducting a quantitative survey in the same target group.

adolescents attending regular high-school education have ever smoked $(34.2 \%)$ compared with adolescents attending vocational training $(63.8 \%)$. The relative difference is even larger when we look at the percentage of daily smokers among adolescents attending regular high-school education (5.2\%) compared with adolescents attending vocational training $\left(28.6 \%\right.$ daily smokers). ${ }^{3}$ 
Since smoking is extremely common in adolescents, research on attitudes and behaviour with regard to smoking in this group is of great importance.

All sold tobacco products in Belgium, have to mention a general health warning on the package. Besides the general warning, a combined warning has to be mentioned, that is, a picture or another illustration together with an accompanying text. These health warnings have to cover $40-50 \%$ of the package, according to whether the message is mentioned in one, two or all three the official languages in Belgium.

However, to decrease the burden of disease caused by smoking, new efforts are needed. Since most forms of tobacco marketing are prohibited by law in the majority of Western European countries, the packaging is one of the last means the tobacco industry has at its disposal to advertise their product. When there is a prohibition of the use of logos, colours, brand images or promotional information on the packaging of tobacco products, it is called plain packaging. The use of brand names and product names is allowed, but they have to be displayed in a standard colour and style. ${ }^{4}$

Following article 13 of the Framework Convention on Tobacco Control (FCTC) to ban tobacco advertising, Freeman et $a \bar{l}$ concluded that cigarette packages should also be considered as publicity and promotional materials. Guidelines concerning article 13 were adopted at the Third Conference of the Parties of the FCTC in 2008, which read 'Parties should consider adopting plain packaging requirements to eliminate the effect of advertising or promotion on packaging.' Moreover, these plain packages seem to be an important intervention in dissuading young non-smokers from becoming smokers and encouraging smokers to quit ${ }^{6}$ or to decrease their cigarette consumption. ${ }^{7}$

Several studies in different countries, such as the UK, Germany, France, New Zealand, Australia and the USA, found that adolescents perceive plain packages as less attractive. $^{8-12}$ Together with the health warnings, which are much more eye-catching on plain packages, ${ }^{13}$ this is more likely to promote cessation among adolescents, especially in non-daily smokers. ${ }^{14}$ Based on qualitative research, Gendall et $a l^{15}$ conclude that the ease with which packaging alone enabled young people to identify brand attributes, shows that tobacco packaging functions as advertising. Although a lot of evidence in different continents is available concerning the potential of plain packaging to influence smoking behaviour in adolescents, cultural and local factors might still play a role. Attitudes, opinions and behaviour concerning smoking differ throughout Europe. For instance: only $41 \%$ of the Belgian population is totally in favour of smoking restrictions in bars, pubs and clubs, while in Italy, this is $87 \%$. Moreover, only $14 \%$ of Belgians thinks that health warnings on tobacco packages are very effective, while this is $46 \%$ in Rumania. ${ }^{16}$ Concerning smoking behaviour, $30 \%$ of Belgians were smokers in 2009, while this was only $16 \%$ in Swedish people. ${ }^{17}$ In Flanders, no study on plain packaging had been done before. For that reason, a qualitative study on plain packaging in Flemish adolescents was performed to rule out erratic results compared to the existing evidence.

Our study aimed at estimating the potential effect of the appearance of a cigarette package on the smoking behaviour of adolescents in Flanders. We explored the motives of young people when choosing a certain cigarette package. Further, we explored the visibility of the warning labels on original and plain packages. This study was financed by the Belgian Foundation Against Cancer.

\section{MATERIALS AND METHODS \\ Focus group discussions}

We explored perceptions of plain packages, using focus group discussions (FGDs). This qualitative research method is very appropriate when exploring opinions, attitudes and experiences. $^{18}$

Preset procedures and rules are agreed on how to conduct FGDs. A FGD is a group conversation with a small homogeneous group of usually 6-10 participants. The moderator conducted the discussion assisted by an observer. The observer has also taken into account the non-verbal behaviours and this was discussed afterwards with the moderator to obtain a more general view of the relative importance of the different motives.

FGDs were recorded and the transcriptions were analysed by means of a specialized software programme, Nvivo 9 following the open coding method.

The focus groups were composed following strict inclusion criteria. A company specialising in market research organised the recruitment with following inclusion criteria:

- 15-year-old to 16-year-old and 17-year-old to 18-year-old adolescents.

- Adolescents attending regular high-school education or vocational training.

- Current or ever smokers.

- Boys and girls (as evenly distributed as possible).

- Region of Antwerp.

It is very important that the FGDs come as close as possible to a natural discussion, which could be hampered when the difference between the age groups and type of educational training is too big. That is why separate FGDs according to age categories (15-16 years and 17-18 years old) and education (regular high-school education and vocational training) were performed.

Moreover, it is very well known that there is a big difference in smoking behaviour between Flemish pupils attending regular high-school education and those attending vocational training. ${ }^{3}$ We conducted eight FGDs, four in pupils attending regular high school (two in pupils aged 15-16 and two in pupils aged 17-18) and four in pupils attending vocational training (two in pupils aged 15-16 and two in pupils aged 17-18). 
A script was used for guidance to ensure that the same questions were dealt with in each FGD, which included a short questionnaire about some characteristics of the participants to get a better idea of their profile (sex, date of birth, age at which first cigarette was smoked, age at which regular smoking started, mean number of cigarettes and mean number of smoking days a week), two to five main questions, which were preceded by an introductory question, one or two transitional questions and a conclusion. To obtain an answer to the research question: 'What motivates young people to choose a certain cigarette package?', several open-ended key questions with sub-questions were formulated to leave enough space to obtain new insights. During the introduction, the course and aim of the FGD were presented. During the first part of the FGD, several popular brand packages were shown to the participants (L\&M, Marlboro, Tigra, Camel and Pall Mall). A picture of the shown brand packages can be found as an online supplementary appendix. Using the real packaging helped the participants to sum up relevant motives for choosing a certain brand. In the second part, only the plain package and the comparable brand package were presented. The motives which were mentioned in the first part of the FGD were then used by the moderator to address the participants and sustain the discussion. During the conclusion of the FGD, the participants had the opportunity to make additional remarks.

The script for the FGD can be found in table 1 .

After each focus group, there was a debriefing with the moderator and the observer concerning the main points of interest, resulting in debriefing notes. The audio recordings of the focus groups were transcribed and the transcriptions were analysed. The qualitative data were analysed following the open coding method. This process was performed multiple times, comparing different focus groups discussions and the responses of different participants, until central themes emerged. To guarantee validation of the analysis, the process was undertaken by a second independent analyst. The results of this coding procedure were then compared with the debriefing notes The results of the FGDs are presented using quotes from the participants (boxes 1-3) and stated whether the respondent was a daily or nondaily smoker. In our study, a smoker is considered a daily smoker when he or she smokes every day of the week. All pupils that reported smoking less than 7 days a week were considered non-daily smokers (including exsmokers, experimental smokers and social smokers). The participants were assigned to the daily smokers group or the non-daily smokers group according to the information on the short questionnaire (mentioned above). In addition, we asked every participant during the introduction of the FGD to identify themselves as a daily or a non-daily smoker. The quotes are presented in English after a free translation, since the original language of communication was Dutch. In the online supplementary appendix, a table can be found in which all participants are situated.

\section{Packages}

When conducting FGDs on plain packaging, it is interesting to have a real example of both the original and the plain package present. When producing the plain packages (developed specifically for this study), the design of the original package was checked meticulously to create a plain package that is as realistic as possible. In this way, the respondents were able to compare the two kinds of packaging without being distracted by irrelevant differences.

For the original package, Marlboro was used. It is a very popular and familiar brand for Flemish young people. However, this choice was rather arbitrary. The differences between the two packages can be seen in figure 1 .

The health warnings, the producer's name and the dimensions were the same for both packages. The reason for choosing the specific health warning 'smokers die younger', with a picture showing the foot of a dead body, in preference to others, was the study result that this health warning and picture seemed to be the most noticed by young people. ${ }^{19}$

\section{RESULTS}

In total, 55 adolescents participated. The mean age the participants started smoking was 13.5 years (median 14 years). The mean age for starting daily smoking was 14.5 years (median 15 years).

We achieved saturation of the data in both the FGDs of the 15-16-year-olds and the FGDs of the 17-year-olds to 18 -year-olds.

\section{Motives of young people in choosing a certain cigarette package}

The motives which were repeatedly mentioned when choosing a certain brand were the price of the brand, the taste of the cigarettes, the influence of the social environment, the recognition of a certain brand and the influence of the packaging (appearance, size and manageability).

As illustrated by quotes 1 and 2 (box 1), the two most important motives were the price and the taste of the cigarettes, and these were more an issue for daily than for non-daily smokers. The participants were quite conscious about their choice when choosing between cigarette brands, a lot of young people considered the combination of the price and quality (for instance a good taste) of the cigarettes (quote 9 , box 1 ).

Our participants seemed to be largely influenced by family and friends when choosing a new brand or switching between brands. This finding was more important for non-daily smokers compared to daily smokers (quotes 3 and 4, box 1). Recognition, appearance, size and manageability of the packages also played a role in the decision-making process, but these were not considered as most important (quotes $5-8$, box 1 ). Non-daily smokers seemed to be more influenced by the 
Table 1 Script for the focus group discussions

\author{
Questions* \\ IQ-Which brand do you smoke? \\ SQ-What determines your choice? \\ SQ-Which brands do your family and friends smoke? \\ $\mathrm{SQ}-$ How does this influence you? \\ SQ-What could make you change brand? \\ $\mathrm{SQ}-$ What has already made you change brand? \\ TQ-What is your opinion about these different brands?
}

SQ —What kind of smokers do you associate with which brands/packages?

SQ-What do you think are important features of a brand?

SQ-What could make you try a certain brand?

$\mathrm{TQ}-$ What is your opinion about these cigarette packages?

SQ-What do you think is important about cigarette packages?

SQ-What role do the colours of the packages play?

SQ-How important is the size of the package?

$\mathrm{SQ}-$ What is your opinion of the illustrations on the packages?

$\mathrm{SQ}-$ Which other brand would you like to try? For what reason?

SQ-Is the taste important? Why (not)?

$\mathrm{KQ}-$ Can you remember what you saw on the two packages?

SQ-What were the differences between the two packages?

SQ-What do you find positive or negative about either package and why?

SQ-What else did you see on the packages?

SQ-Which health warnings did you see on the two packages?

SQ-On which package did you see these health warnings?

$\mathrm{SQ}-$ What were the differences between the two packages?

SQ-What do you find positive or negative about either package and why?

SQ-What else did you see on the packages?

SQ-Which health warnings did you see on the two packages?

SQ-On which package did you see these health warnings?

$\mathrm{KQ}$-Of all the motives that were mentioned earlier, what is the most important

motive for choosing a certain brand?

$\mathrm{KQ}$-If something were to change (eg, price increase), how would this influence your smoking behaviour?

Closing of the FGD

\section{Rationale/comments}

This question was asked to enable further acquaintance with the participants and gradually focus the discussion on to the study topic

Only when the discussion stagnated were these sub questions used

This question was asked to guarantee a fluent transition from the introduction to the key question. The participants were shown packages of some popular brands. Motives for choosing a certain brand were explored

Only when the discussion stagnated, these sub questions were used

In addition, we wanted to explore the opinions and attitudes concerning the packaging of the different brands. Therefore, we asked an open question and some sub-questions

After taking away the different packages of the popular brands, two packages were passed around: one original package and one plain package of the same brand

After taking away the original and the plain package, this key question was asked to check spontaneous recollection

After the spontaneous recollection, the same questions were asked again when the two packages were distributed a second time

At the end of the FGD, the participants were given the opportunity to come up with additional remarks or suggestions

*FGD,focus group discussion; IQ, introductory question; $K Q$, Key question; $S Q$, sub question; $T Q$, transition question. 
appearance of the cigarette package than daily smokers (quote 6 , box 1 ).

During the FGDs, the original and plain package were compared and the respondents were asked which package they preferred and why. The colour was experienced as an important difference between the two packages. This was immediately linked with attractiveness. The original package in red was considered as more attractive. Moreover, it was mentioned in the FGDs that young smokers would be restrained to buy a cigarette brand in plain package just because it is unattractive (quote 10, box 2).

Participants linked the appearance of the package with the quality of the cigarettes. The plain package seemed to them as cheaper and of lower quality than the original red package (quotes 11 and 12, box 2). Also, the lack of additional information on the plain

\section{Box 1 Motives for choosing a certain brand}

1. PRICE. 'For me, especially the price is important. You see, when I have just received my pocket money, I can buy a more expensive brand but by the end of the week, I really have to start counting my money' (Female daily smoker, 17 year).

2. TASTE. 'Yes, of course. Yes, BRAND $X$ tastes so heavy and nasty. You see, it is just like smoking camel's hair' (everybody starts to laugh) (Male daily smoker, 18 year).

3. INFLUENCE OF THE SOCIAL ENVIRONMENT. 'I guess I would take brand $\mathrm{X}$, just because a lot of people smoke it. I don't know much about it, so...' (Female non-daily smoker, 16 year).

4. HABIT. 'Because of my mother, she also always smokes BRAND $X$ and those were the first cigarettes that I tried and I became attached to them, more as a habit' (Female daily smoker, 19 year).

5. RECOGNITION. 'The one you know best. For me these are BRAND X, BRAND Y, and BRAND Z. You see, I just recognize the packaging' (Male non-daily smoker, 15 year).

6. INFLUENCE OF THE PACKAGE-APPEARANCE. 'The package doesn't matter, those are simply the most popular cigarettes.' (Female daily smoker, 19 year). 'I would look at the packages because I don't know how all these different brands taste.' (Male non-daily smoker, 17 year).

7. INFLUENCE OF THE PACKAGE-SIZE. 'I mostly like small packages. Then it seems as if you smoke less. Of course, you have to buy more then. But with such a large package in your bag, people tend to think you smoke a lot' (Female daily smoker, 19 year).

8. INFLUENCE OF THE PACKAGE-MANAGEABILITY. 'That's an inconvenient package (referring to one of the brand packages). You cannot close it once it has been opened. Once it is open, you have to put your cigarettes somewhere else, otherwise you lose them all' (Female daily smoker, 16 year).

9. COMBINATION OF PRICE AND TASTE. 'But then you are not going to buy the extremely expensive ones, are you? It's just the same as when you drive a Porsche, because, you know, that's extraordinarily good but you're not going to buy that immediately, are you, because it's better? You really have to steer a middle course' (Male non-daily smoker, 15 year).
Box 2 Appearance of the plain package vs the original package

10. 'Such a package that has no colour at all, that would not appeal to me to buy it. I don't know why, but... probably because it simply looks bad. That's why I would never buy such a white package.' (Male daily smoker, 15 year).

11. 'The white package seemed like something of only one euro in the shop' (Male daily smoker, 15 year).

12. 'Subconsciously, people will think that the quality is lower (of the cigarettes in the plain package), I think' (Female non-daily smoker, 17 year).

13. 'It depends, I think people would be confused and wonder whether it is the same as before, if they are used to buying brand $\mathrm{X}$. Are they the same? Do they taste the same? And I think fixed users of brand $X$ won't change brands, only those who smoke brand $X$ occasionally (...).' (Female daily smoker, 19 year).

package increased the feeling of mistrust in young smokers. On the contrary, the commercial messages on the packages increased the feeling of familiarity and recognition.

An important distinction is observed between daily and non-daily smokers. Daily smokers said they would not adjust their smoking behaviour because of a change in the appearance of their cigarette package (quote 13, box 2 ).

No differences in attitudes concerning plain packages were found according to age categories and gender.

In all focus groups, discussion arose spontaneously on the pros and cons of the health warnings on the packages. Opinions on the possible effect of the warnings were mixed. In general, the health warning

\section{Box 3 Visibility and effect of the health warnings}

14. 'I don't think that there is a big influence on daily smokers But people who are going to buy their first package might think: 'I would better not be doing that' (Female daily smoker, 16 year).

15. 'Yes, I think it really helps to quit smoking. When I take it out of my backpack, I think: 'Shit, maybe I look like that inside'. So, yes, it makes me think about quitting" (Female daily smoker, 16 year).

16. 'I found that, with all that white, the health message was much clearer: smoking kills' (Male daily smoker, 15 year).

17. 'Simply the white package, it was so dull, so you notice the picture better, it is in the spotlight compared to the picture on the red package. The white package is more effective and because the name of the brand is smaller and not in bold, the text underneath catches the attention much more' (Male non-daily smoker, 16 year).

18. 'Yes, the message 'smoking kills' and then on the back the picture... The message catches the attention much more on the white package. I don't know why but it certainly was the case. I mean, you would more likely believe the message on the white package'. (Male daily smoker, 18 year). 
Figure 1 Plain package and original package: front.

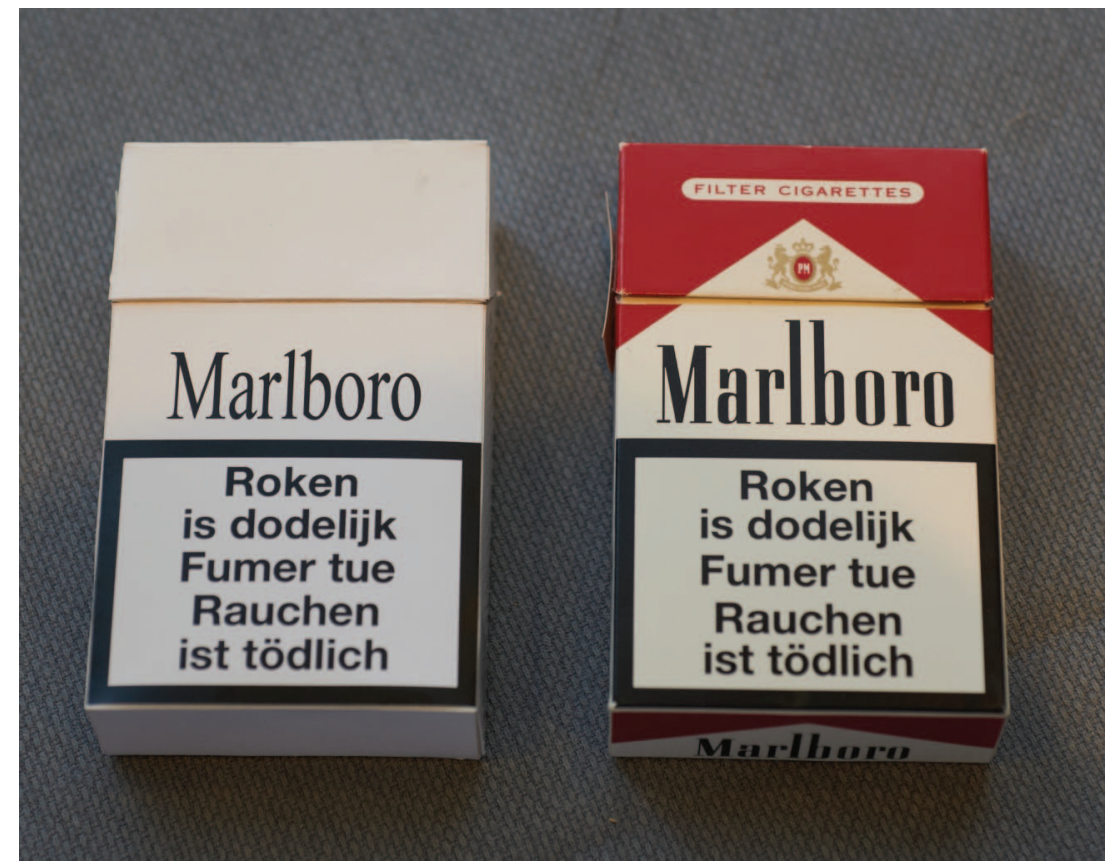

messages were much more noticed on the plain packages (quotes 16 and 17, box 3). This was the case for daily as well as non-daily smokers. Moreover, respondents mentioned that the health warning message on the plain package was much more trustworthy (quote 18 , box 3$)$.

Quote 14, box 3, illustrates an opinion that was shared with several other respondents in that FGD. Daily smokers spoke about the possible effect plain packaging may have on the smoking behaviour of non-daily smokers. This seems to be a recurrent phenomenon: young people reflecting on others' behaviour (also illustrated in quote 13, box 2). The striking difference between daily and non-daily smokers was an opinion that was shared in most FGDs.

\section{DISCUSSION}

Our study shows that the most important motives for young people to choose a certain brand of cigarettes are the price of the cigarettes, the taste of the cigarettes, the influence of the social environment and the recognition of the packaging. Daily smokers seem to be less influenced by the above mentioned motives. Despite big differences in smoking behaviour, we did not find differences in attitudes and opinions concerning plain packaging between adolescents attending regular high-school education and those attending vocational training. This could be an indication of the fact that the educational discipline is less important compared with daily or non-daily smoking when it comes to plain packaging. Since almost one of three Flemish smokers aged 15-24 is a non-daily smoker, this opens up a lot of opportunities for health gain.
Internal tobacco industry documents from several countries reveal that the tobacco industry actively targets young people. ${ }^{20-23}$ Since many countries have introduced severe restrictions or even a total advertising ban for tobacco products, the possibilities for tobacco publicity are limited. The tobacco industry therefore tries to make the appearance of the package or the cigarette as attractive as possible. Some producers have even experimented with square instead of round cigarettes. At the same time this possibly camouflages the many health dangers of smoking. ${ }^{24}$ It could even be suggested that cigarette packages as they are nowadays commercially available, undermine certain rules of the current EU Tobacco Products Directive 2001/37/EC, which prohibits misleading description. ${ }^{25}$

A possible answer of the government to this manoeuvre of the tobacco industry to create publicity, is plain packaging. Australia was the first country to adopt this legislation, which will make plain tobacco packaging compulsory in December 2012. In Belgium, a member of the federal parliament has made a proposal to introduce plain packaging. ${ }^{26}$ An important feature in that respect, is that introducing plain packaging is free of costs for the government.

The main question is whether plain packaging is effective or not. In other words, are adolescents susceptible to the appearance of cigarette packages? Our study suggests that plain packages are perceived as less attractive, cheap and unreliable for young people. Other authors have obtained similar results over the past 20 years. ${ }^{792728}$ Because of the unattractiveness of the plain packaging, the health warnings catch the eye much more effectively. This is also in line with other studies, where young people could remember the health 
warnings on plain packages more easily. ${ }^{27} 28$ On the other hand, our results show that the health warnings on plain packages were considered to be more trustworthy than on the brand packages, something that was also found in a study by Rootman and Flay. ${ }^{29}$ These findings suggest a bigger impact on smoking behaviour of health warnings on plain packages compared to health warnings on original packages. At this time, $70 \%$ of the parties to the WHO FCTC have already introduced big, unambiguous and clearly visible health warnings on cigarette packages. $^{30}$

The tobacco industry argues that introducing plain packaging would lead to more illicit tobacco on the market. However, Moodie $e t a l^{31}$ have demonstrated that this line of reasoning is groundless, given that the costs of manufacturing cigarettes for the illicit market are so low that presence of branding on packaging is unlikely to impact upon these costs in any meaningful way.

Nevertheless, further research on plain packaging is necessary. In our study, for instance, the plain package was constructed in close co-operation with the funders of the study. The quality of the plain packaging is, of course, an important feature when comparing the plain and the original packaging in FGDs. After all, a plain package that is unrealistic or of a lesser quality, could influence the results of the study. Although every possible effort was made, the plain packaging that finally resulted was still not of 'factory quality'. This was due to the high cost of developing only a few pieces of plain packaging of professional quality. Although the quality of the plain packaging was never mentioned during the FGDs, it has to be borne in mind for future studies.

Further research could take into account a participants' nicotine dependence, for instance, by using the Fagerström test. This could possibly offer an explanation for the difference between daily and non-daily smokers that we found in our study.

The qualitative research method gave us a unique insight into the opinions and perceptions of young smokers regarding the impact of cigarette packaging on smoking behaviour. To generate more representative data, however, validating our findings by conducting a quantitative survey in the same target group is recommended.

Nevertheless, the fact that our results are in line with other studies, makes us more confident about the validity of our results and the fact that plain packaging can make smoking less attractive for young people.

We therefore believe that introducing plain packaging in Belgium can result in a substantial health gain in young people.

Acknowledgements The authors would like to thank all pupils who participated in the focus group discussions, the recruitment agency (Field Quality Control, Itd.) that recruited the pupils and the Belgian Foundation Against Cancer for funding this study.

Contributors VHG and VRS substantially contributed to conception and design, analysis and interpretation of data. VB participated in revising the article critically for important intellectual content. AM substantially contributed to acquisition of data. HS substantially contributed to conception and design, revising the article critically for important intellectual content. FJ substantially contributed to conception and design, acquisition of data, analysis and interpretation of data.

Funding The Belgian Foundation Against Cancer only did the (limited) financing of this study to have scientific data on Flemish adolescents' perceptions regarding plain packaging.

\section{Competing interests None.}

Ethics approval The recruitment of the respondents was organised by a company specialising in market research. They have a database of possible respondents at their disposal and collected an informed consent for each of the participating respondents. Moreover, anonymity was guarded throughout the focus group discussions

Provenance and peer review Not commissioned; externally peer reviewed.

Data sharing statement An extensive report of this study is available with the researchers (in Dutch). The same holds for the debriefing notes and the coding notes of the researchers and all verbatim transcripts of the focus group discussions. These documents can be provided by the corresponding author: Guido Van Hal, guido.vanhal@ua.ac.be.

Correction notice This paper has been corrected since it was first published. Citations to the boxes in this article have been corrected.

\section{REFERENCES}

1. Gisle L. Use of tobacco. Health Interview Survey, Belgium 2008. Brussels: Scientific Institute of Public Health-Department of Epidemiology, 2010 (in Dutch).

2. Internal Affairs Flanders: http://www4.vlaanderen.be/dar/svr/Cijfers/ Pages/Excel.aspx. Data population pyramid. (accessed on $21 \mathrm{Mar}$ 2012).

3. Kinable H. Pupils' survey as part of an alcohol and drug policy at school. Summary report school year 2008-2009. In: Bernaert I, De Maeseneire I, Geirnaert M, Rosiers J eds. Association for alcohol and other drug problems. Brussels, 2010 (in Dutch).

4. Selin H, Sweanor D. UICC Tobacco Control Fact Sheet No. 16. Generic packaging. Towards Informed Consent: the case for plain packaging of tobacco products. Canada: International Union Against Cancer, 1996.

5. Freeman B, Chapman S, Rimmer M. The case for the plain packaging of tobacco products. Addiction 2008;103:580-90.

6. Lencucha R. Philip Morris versus Uruguay: health governance challenged. Lancet 2010;376:852-3.

7. Cunningham R, Kyle K. The case for plain packaging. Tob Control 1995;4:80-6.

8. Germain D, Wakefield MA, Durkin SJ. Adolescents' perceptions of cigarette brand image: does plain packaging make a difference? J Adolescent Health 2010;46:385-92.

9. Hammond D, Dockrell M, Arnott D, et al. Cigarette pack design and perceptions of risk among UK adults and youth. Eur J Public Health 2009;19:631-7.

10. Moodie C, Mackintosh A, Hastings G, et al. Young adult smokers' perceptions of plain packaging: a pilot naturalistic study. Tob Control 2011;20:367-73.

11. Doxey J, Hammond D. Deadly in pink: the impact of cigarette packaging among young women. Tob Control 2011;20:353-60.

12. Brown A, McNeill A, Mons U, et al. Do smokers in Europe think all cigarettes are equally harmful? Eur J Public Health 2012;22 (Suppl 1):35-40.

13. Hoek J, Wong C, Gendall P, et al. Effects of dissuasive packaging on young adults smokers. Tob Control 2011;20:183-8.

14. Munafo M, Roberts N, Bauld L, et al. Plain packaging increases visual attention to health warnings on cigarette packs in non-smokers and weekly smokers but not daily smokers. Addiction 2011;106:1505-10.

15. Gendall P, Hoek J, Thomson G, et al. Young adults' interpretations of tobacco brands: implications for tobacco control. Nicotine Tob Res 2011;13:911-18.

16. The Gallup Organisation upon request of the Directorate General Health and Consumers. Flash Eurobarometer 253-Survey on Tobacco. Analytical report, 2009. 
17. TNS Opinion \& Social at the request of Directorate General Health and Consumers. Special Eurobarometer 332 / Wave 72.3-Tobacco, 2010.

18. Vermeire E, Van Royen P, Griffiths F, et al. The critical appraisal of focus group research articles. Eur J Gen Pract 2002;8:104-8.

19. UK Department of Health. Consultation on the introduction of picture warnings on tobacco packs. London: Department of Health, 2006.

20. Moodie C, MacKintosh AM, Brown A, et al. Tobacco marketing awareness on youth smoking susceptibility and perceived prevalence before and after an advertising ban. Eur J Public Health 2008;18:484-90.

21. Hastings G, MacFadyen L. A day in the life of an advertising man: review of internal documents from the UK tobacco industry's principal advertising agencies. Brit Med J 2000;321:366-71.

22. Cummings KM, Morley CP, Horan JK, et al. Marketing to America's youth: evidence from corporate documents. Tob Control 2002;11 (Suppl I):i5-17.

23. Wen $\mathrm{CP}$, Chen $\mathrm{T}$, Tsai $\mathrm{Y}-\mathrm{Y}$, et al. Are marketing campaigns in Taiwan by foreign tobacco companies targeting young smokers? Tob Control 2005;14:i38-44.

24. Hastings G, Gallopel-Morvan K, Rey JM. The plain truth about tobacco packaging. Tob Control 2008;17:361-2.
25. Moodie $\mathrm{C}$, Hastings $\mathrm{G}$. Plain packaging: a time for action. Eur $\mathrm{J}$ Public Health 2010;20:10-11.

26. Fonck C, Burgeon C, Snoy et d'Oppeurs T, et al. Proposition de lo modifiant la loi du 24 janvier 1977 relative à la protection de la santé des consommateurs en ce qui concerne les denrées alimentaires et les autres produits et visant à l'instauration d'un paquet de cigarettes neutres. Chambre des représentants de Belgique, 19 avril 2011. DOC 53 1424/001.

27. Beede $\mathrm{P}$, Lawson $\mathrm{R}$. The effect of plain packages on the perception of cigarette health warnings. Public Health 1992;106:315-22.

28. Goldberg ME, Liefeld J, Madill J, et al. The effect of plain packaging on response to health warnings. Am J Public Health 1999;89:1434-5.

29. Rootman I, Flay B. A study on youth smoking plain packaging, health warnings, event marketing, and price reductions key findings. Centre for Health Promotion. Toronto, Canada: University of Toronto, 1995.

30. Nikogosian H. WHO Framework Convention on Tobacco Control: a key milestone. Bull World Health Organ 2010;88:83.

31. Moodie C, Hastings G, Joossens L. Young adult smokers' perceptions of illicit tobacco and the possible impact of plain packaging on purchase behaviour. Eur J Public Health 2012;22:251-3. 


\section{Correction}

Van Hal G, Van Roosbroeck S, Vriesacker B, et al. Flemish adolescents' perceptions of cigarette plain packaging: a qualitative study with focus group discussions. BMJ Open 2012;2: e001424. There were errors in the citations to the boxes in this article. We have since corrected the online version.

BMJ Open 2013;3:e001424corr1. doi:10.1136/bmjopen-2012-001424corr1 